\title{
Accidental Surgical Division of Lateral Cutaneous Nerve of Thigh
}

\author{
K. HINGORANI,* M.R.C.P.ED., M.R.C.P.GLASG., D.PHYS.MED.
}

Brit. med. F., 1964, 1, 607-608

Lesions of the lateral cutaneous nerve of the thigh may occur for various reasons. Four cases are here reported where impairment of sensation in the distribution of the lateral cutaneous nerve of the thigh occurred after an incision for removal of bone from the iliac crest for grafting elsewhere. Two of these patients suffered severe burns. The anatomical variations of the course of this nerve have been pointed out by Ghent (1961). Originating from the dorsal branches of anterior primary rami of the second and third lumbar nerves, it emerges from the lateral border of the psoas major and, crossing the iliacus obliquely, runs towards the anterior superior iliac spine. It may then take any of the following four routes: (1) passing through a "split" inguinal ligament; (2) going beneath the ligament ; (3) passing through the belly of the sartorius muscle ; or (4) crossing superficially where it is easily compressed by encircling garments. In the thigh it divides into an anterior and a posterior branch ; the anterior branch is distributed to the skin of the anterior and lateral parts of the thigh as far as the knee. The posterior branch pierces the fascia lata at a higher level than the anterior branch and subdivides into filaments which pass backwards to supply the skin on the lateral surface of the limb from the level of the greater trochanter to about the middle of the thigh.

\section{Case Reports}

Case 1.-On 20 August 1961 a man aged 45 was admitted to hospital with a comminuted fracture of the right tibia and fibula due to a motor-cycle accident. The fracture was treated initially by manipulation and a full leg plaster. On 11 May 1962 a bonegrafting operation was performed on the right tibia, slivers of bone being taken from the anterior half of the left iliac crest through a 6-in. (15-cm.) incision (Fig. 1). The second day after the operation the patient noticed absence of feeling over the outer aspect of the left thigh. About the middle of October, while having heat treatment to the right leg, his left thigh came into contact with a radiator pipe, whereby he sustained a third-degree burn (Fig. 1), which, however, he did not notice until about 10 minutes later, when he accidentally happened to touch the area. Examination showed absence of sensation over the distribution of the lateral cutaneous nerve of the thigh.

Case 2.-On 5 May 1962 a man aged 38 fell and fractured both his calcanea. He was put in plaster until 10 May, when subtalar arthrodesis of the right foot was performed, during which chips from the right iliac crest were removed to be used in the operation (Fig. 2). An above-knee plaster extending to the junction of the middle and upper thirds of the thigh was applied after the operation and retained for seven weeks; then it was changed to a below-knee plaster for another seven weeks. He first noticed numbness over the outer aspect of the right thigh some two weeks after the bone-grafting operation. About the middle of October, while having a bubble-bath for his feet, his right leg accidentally came in contact with a dripping hot-water-tap and he sustained a second-degree burn of the thigh which he failed to notice until a few hours later (Fig. 2). Loss of sensation over the distribution of the lateral cutaneous nerve of the thigh was confirmed on examination.

* Senior Registrar in Physical Medicine, Durham Miners' Rehabilitation Centre, The Hermitage, Chester-le-Street, Co. Durham. (Now Consultant in Physical Medicine and Rheumatology, Gateshead Group of Hospitals, Gateshead.)
Case 3.-On 8 April 1962 a man aged 45 fractured the lower third of the left tibia. The fracture was reduced and put into a standard above-knee plaster which was changed on 11 April with remanipulation of the fracture under a general anaesthetic. On 23 April the procedure was repeated as the fracture had slipped. Owing to marked osteoporosis and evidence of non-union on 14 September, a bone-grafting operation was undertaken. An incision over the iliac crest was made and bone chips were removed. The leg was then immobilized in an above-knee plaster. On 18 November the plaster was taken off and about a fortnight later the patient

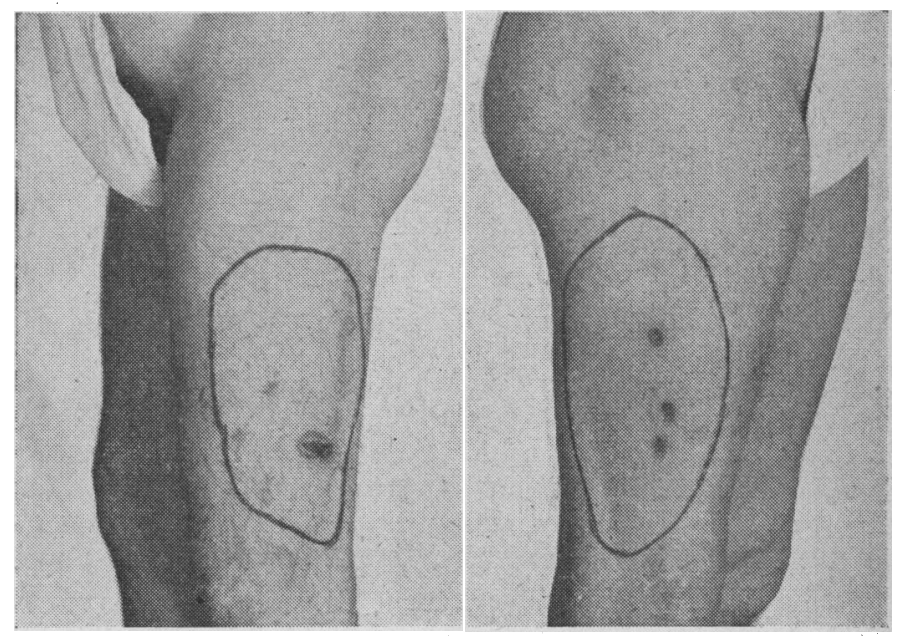

Fig. 1.-Case 1.

Fig. 2.-Case 2 .

noticed absence of feeling over the outer aspect of the left thigh, which on examination was found to be in the distribution of the lateral cutaneous nerve.

Case 4.-On 16 November 1961 a man aged 47 sustained a fracture of the left tibia and fibula just below the knee following a road accident. Manipulation was performed and the limb put in an above-knee plaster. In September 1962 the fracture was found to be un-united and a bone-grafting operation was undertaken on 26 October. An oblique lateral incision was made which extended to the anterior superior iliac spine, and bone chips for grafting were obtained. A few days after this operation the patient noticed a feeling of numbness over the lateral aspect of the left thigh, and on examination hypoaesthesia and hypoalgesia were found over the distribution of the lateral cutaneous nerve of the thigh. The sensation, however, was gradually returning and it would seem that the nerve had been merely contused during the operation without suffering lasting damage.

\section{Discussion}

The four patients reported in this paper had all undergone bone-grafting operations; the incision in three cases extended anteriorly beyond the anterior superior iliac spine, thus damaging the lateral cutaneous nerve of the thigh permanently, with consequent loss of sensation. In Cases 1 and 2 severe burns were sustained as a result of this damage. In Case 3 there was loss of sensation without superadded complications, while in 
Case 4 the nerve escaped permanent damage owing to the incision having been restricted anteriorly to the anterior superior iliac spine. Awareness of this complication would lead to its prevention. Because of unpredictable variation in the course of the lateral cutaneous nerve of the thigh, the incision should not be extended anteriorly beyond the anterior superior iliac spine. It is possible that in many cases these lesions go undetected owing to absence of complications.

\section{Summary}

Because of its variable anatomical course, the lateral cutaneous nerve of the thigh is vulnerable to incisions made for operations involving removal of bone from the iliac crest. In three of the four cases here reported the nerve was damaged by incision which extended anteriorly beyond the anterior superior iliac spine. In the fourth patient sectioning of the nerve was avoided because the incision was restricted to the anterior superior iliac spine, but the nerve was nevertheless contused during the operation, producing temporary sensory impairment.

I am grateful to Dr. A. Zinovieff for his guidance. I would like to thank Miss R. Shotton, of the photographic department, and Mrs. E. Bulmer for their help and co-operation.

\section{REFERENCE}

Ghent, W. R. (1961). Canad. med. Ass. F., 85, 871.

\section{Preliminary Communications}

\section{Iron Absorption in Cystic Fibrosis}

\section{Brit. med. F., 1964, 1,"608-609}

The absorption of iron in cystic fibrosis has become of great interest since recent reports demonstrating the influence of the pancreas on iron absorption. Davis and Badenoch (1962) showed that iron absorption was increased in chronic pancreatitis; administration of pancreatin decreased iron absorption in haemochromatosis (Biggs and Davis, 1963) and in hepatic cirrhosis (Callender and Malpas, 1963). The results of the present study show that children with cystic fibrosis treated with pancreatin absorb iron poorly, and may develop a mild iron-deficiency anaemia.

\section{Patients Studied}

Fifteen children with cystic fibrosis were studied (see Table): the diagnosis in each case was established by sweat electrolyte measurements and the absence of tryptic activity in the duodenal juice. The controls were convalescent children between 2 and 12 years old without haematological or gastro-intestinal disorders; all had haemoglobin levels above $12 \mathrm{~g} . / 100 \mathrm{ml}$. and plasma iron values within normal range (80-150 $\mu \mathrm{g} . / 100 \mathrm{ml}$.).

\begin{tabular}{|c|c|c|c|c|c|c|}
\hline \multicolumn{7}{|c|}{ Summary of Patients With Cystic Fibrosis } \\
\hline $\begin{array}{l}\text { Case } \\
\text { No. }\end{array}$ & Sex and Age & $\begin{array}{c}\text { Duration } \\
\text { of } \\
\text { Pancreatin } \\
\text { Treatment }\end{array}$ & $\begin{array}{c}\text { Haemo- } \\
\text { globin } \\
(\mathrm{g} . / \\
100 \mathrm{ml} .)\end{array}$ & $\begin{array}{c}\text { Plasma } \\
\text { Iron } \\
(u \mathrm{~g} . / \\
100 \mathrm{ml} .)\end{array}$ & $\begin{array}{c}\text { Total } \\
\text { Iron- } \\
\text { binding } \\
\text { (ug./ } \\
100 \mathrm{ml} .)\end{array}$ & $\begin{array}{l}\text { Per Cent. } \\
\text { Absorp- } \\
\text { tion } \\
\text { Haemo- } \\
\text { globin- } \\
\text { iron }\end{array}$ \\
\hline $\begin{array}{r}1 \\
2\{ \\
3 \\
4 \\
5 \\
6 \\
7 \\
8 \\
9 \\
10 \\
11 \\
12 \\
13 \\
14 \\
15\end{array}$ & 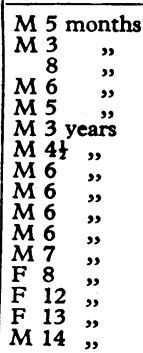 & 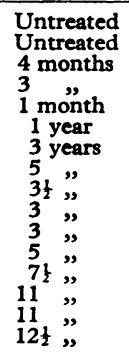 & $\begin{array}{l}12.0 \\
11.3 \\
11.4 \\
10.6 \\
11.0 \\
11.8 \\
10.0 \\
9.0 \\
11.0 \\
11.8 \\
11.3 \\
11.0 \\
12.2 \\
11.9 \\
12.6 \\
12.1\end{array}$ & $\begin{array}{r}31 \\
112 \\
25 \\
33 \\
100 \\
77 \\
33 \\
61 \\
40 \\
70 \\
49 \\
36 \\
84 \\
22 \\
48 \\
38\end{array}$ & $\begin{array}{c}\text { Not done } \\
305 \\
325 \\
318 \\
312 \\
459 \\
\text { Not done } \\
290 \\
372 \\
276 \\
272 \\
315 \\
393 \\
270 \\
325 \\
336\end{array}$ & $\begin{array}{r}19 \cdot 0 \\
30.5 \\
22 \cdot 0 \\
14.0 \\
16.0 \\
11.5 \\
5.5 \\
5 \cdot 0 \\
12.5 \\
6.0 \\
7.0 \\
12.5 \\
4.0 \\
4.5 \\
8.0 \\
6.5\end{array}$ \\
\hline
\end{tabular}

\section{METHODS}

Plasma iron and total iron-binding capacity were measured by the method of Ramsay (1957). Iron absorption was measured by the administration, after an overnight fast, of a quantity of ${ }^{59} \mathrm{Fe}$-labelled rabbit haemoglobin containing $5 \mathrm{mg}$. of iron, with the exception of infants under 2 years, who received $2 \mathrm{mg}$. of iron. The dose was mixed with blackcurrant juice and given to the older children as a drink, or

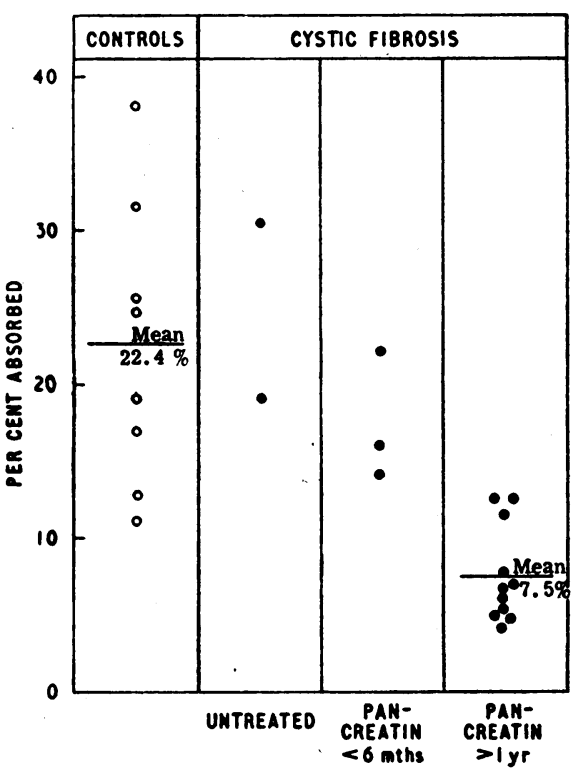

FIG. 1.-Iron absorption in cystic fibrosis.

to the babies in a feeding-bottle. The unabsorbed radioactivity in the stools was measured in a large-well plastic phosphor scintillation counter. The dose of radioactivity administered varied between 0.07 and $0.2 \mu \mathrm{c}$.

\section{RESUlts}

Nearly all the children with treated cystic fibrosis who had received pancreatin for over one year had haemoglobin levels 